\title{
TUNING IN TO KIDS: A PILOTING STUDY TARGETED TO SUPPORT TURKISH PARENTS' EMOTION SOCIALIZATION*
}

\author{
Ayca Ulker Erdem ${ }^{1}$, Mubeccel Gonen ${ }^{1}, \&$ Sophie Havighurst ${ }^{2}$ \\ ${ }^{1}$ Hacettepe University, Department of Early Childhood Education (Turkey) \\ ${ }^{2}$ University of Melbourne Department of Psychiatry (Australia)
}

\begin{abstract}
This study examined the contribution of Tuning in to Kids (TIK) Program on emotion socialization practices of Turkish parents as well as reducing preschoolers' emotional and behavioral problems. TIK is an evidence-based parenting program particularly teaches parents emotion coaching skills, which is to recognize, understand and respond to children's emotions in a reassuring way. Randomized controlled trials of TIK have found increases in parent emotion coaching and child emotion knowledge, and reductions in difficult child behaviors. On this basis, TIK helps parents to develop appropriate emotion socialization skills. When emotion socialization studies conducted with parents in Turkey are examined, significant numerous research on parents' emotion socialization has been documented; however, an intervention targeted to support emotion socialization practices of parents has never studied in this context. In this regard, the effectiveness of TIK Program among Turkey sample was examined in the current research. As a first stage TIK was adapted to Turkish under the guidance of field experts and a pilot implementation was performed. The content of program was organized in terms of clearance, comprehensibleness and applicability. In the second stage, a quasi experimental design was used to consider program impact on certain parent and child outcomes. Ethical permits to conduct this research was obtained by the Ethics Committee of the researcher's university. With the approval of ethics committee, researchers obtained the required informed assents of all parents. 60 parents, who has at least one child between three to six years old, were recruited via preschools and were assigned in experiment and wait list control groups according to their demographics. Parents filled a battery of assessment in order to assess their emotion socialization practices and to rate their children's emotional and behavioral problems. Parents in experiment condition participated in the 6 session TIK program between pre and posttests. They learnt emotion coaching skills and how to regulate their own emotions throughout the sessions. Follow up assessments were employed to examine retention effects. Data analysis was performed using a mixed model ANOVA. Preliminary results showed that program completion rates were high. Most of the participants reported high satisfaction with the program. There are statistically significant improvements in parents' non-supportive emotion socialization practices between pretests and posttests $(F(1,55)=20.464, p<0.01)$. However, there is no significant improvement was seen in children's parent-reported outcomes. This study which explores the potential use of TIK in Turkey sample is thought to make a significant contribution to the field. All the findings would be evaluated to use Tuning into Kids Program for early childhood education settings in Turkey.
\end{abstract}

Keywords: Emotion socialization, parenting program, early childhood, early intervention, tuning in to kids.

*This research covers a part of the first author's doctoral dissertation under the supervision of the second and the third author and supported by The Scientific and Technological Research Council of Turkey- TUBITAK. 